\title{
Antara Ziarah Religius dan Kapitalisasi di Era Globalisasi: Catatan Etnografis Umrah
}

\author{
DOI 10.18196/AIIJIS.2016. 0057.114-134
}

\begin{abstract}
AL MAKIN
Universitas Islam Negeri Sunan Kalijaga, Yogyakarta - Indonesia

Email:almakin3@gmail.com
\end{abstract}

ABSTRACT

This article is written based on ethnographical notes, through observation, interviews, and direct involvement in the lesser pilgrimage (umroh) to Medina on March 12-20, 2016. The writing focuses on the performance of the ritual and other factors which have influenced the development of the holy city from social, economic, and cultural perspectives making the modern city of Medina. This article reveals that Medina as a holy city of pilgrimage destination grows with modern capitalism with the mushrooming business in accommodation and world products. Not only does the religion of Islam mix with capitalism, but the combination of the two does not decrease the sacrality of the city and the performance of the rituals in the city. In fact, the sacrality and holiness remain intact amidst commercialization of the city in the forms of luxuriouos hotels, malls, and modern kiosks. What is more, modern Medina is a symbol of plurality with the Muslim visitors for pilgrimage coming from different countries who bring their own local cultures and various religious traditions seen in their diverse fashions, traditions, and religious rites.

Keywords: religiosity, religious commodifications, umrah

\section{ABSTRAK}

Tulisan ini berasal dari data etnografi, catatan, observasi, wawancara dan pengalaman langsung ziarah umroh ke Madinah pada tanggal 12-20 Maret, 2016. Catatan yang berfokus pada ritual dan faktor yang mempengaruhi Madinah modern dari sisi sosial, ekonomi, dan budaya untuk berusaha memotret Madinah dari berbagai sudut. Dalam artikel ini ditemukan potret Madinah sebagai kota tujuan ibadah ziarah dan juga sekaligus kapitalisasi modern dengan menjamurmnya bisnis akomodasi dan produk-produk dunia. Tidak hanya fenomena agama berbaur dan akrab dengan dunia kapitalisme, namun juga penyatuan keduanya tidak menyurutkan ritualitas keagamaan. Kenyataannya, kesucian kota itu tetap terjaga ditengah komersialisasi Madinah dengan maraknya kemegahan hotel, mall, dan kios-kios. Madinah modern juga sekaligus menjadi penanda pluralnya kaum Mus- 
lim dunia dengan membawa budaya dan tradisi keislaman yang berbeda-beda terlihat dari mode pakaian, tradisi, dan praktek keagamaan dalam ziarah di kota itu.

Kata kunci: relijiusitas, komodifikasi agama, umrah

\section{PENDAHULUAN}

Artikel ini didasari data penelitian etnografis pada tanggal 12-20 Maret, 2016 dalam ibadah umrah yang diselenggarakan oleh Darul Hijrah Tour dan Travel, Cilacap, Jawa Tengah bekerjasama dengan PT. Marco Jakarta dengan izin Kementerian Agama No. 344/2015. Penelitian dan observasi ini tentu juga sekaligus pelibatan langsung peneliti dalam ibadah umrah tersebut dan dengan begitu memberikan nuansa data dan interpretasi yang didasarkan pada pengalaman, wawancara, observasi dengan interpretasi etnografis. ${ }^{1}$ Selain itu, makalah ini dilengkapi dengan data sejarah dari literatur yang memadai dalam melacak kota Madinah. Ibadah umrah tersebut dipimpin oleh Abu Syauqi, direktur Darul Hijrah Tour dan mutawwif (pemandu) oleh Arifin yang sudah bermukim di Mekah selama tujuh tahun. Rombongan itu terdiri dari tiga puluh orang dari berbagai profesi, mulai dari pegawai bank, nelayan, petani, guru, kiai, pedagang, pensiunan pegawai negeri sipil dan lain-lain. Asal muasal kota para peserta ibadah juga berbeda-beda: Jakarta, Yogyakarta, Pati, Banyumas, Cilacap, dan Bandung. ${ }^{2}$ Data didapat dari observasi, wawancara dengan peserta dan pelibatan langsung, juga mendapatkan data dari peserta umrah selama di Madinah yang berasal dari negara lain, di antaranya: Pakistan, India, Mesir, dan Uzbekistan. Data yang terekam dan tercatat kemudian diolah sedemikian rupa dan diceritakan secara naratif untuk sampai pada kesimpulan penggambaran Madinah dari berbagai segi. Observasi di sekitar kota Madinah juga dijalani langsung.

Untuk pembahasan dalam tulisan ini dibagi ke dalam beberapa bagian yaitu: tentang unsur kesejarahan Madinah itu sendiri dengan dukungan literatur yang memadai, juga fungsi dan perubahan kota itu dari waktu ke waktu disinggung secara singkat, kemudian langsung memaparkan hasil observasi lapangan. Hasil observasi dibagi ke dalam beberapa tema yang meliputi perkembangan terkini kota itu dari segi fasilitas struktur dan infrastruktur, keadaan ekonomi dan kegiatan bisnis, ibadah para peziarah, suasana di Masjid al-Haram Nabawi yang meliputi juga raudah dan museum. Artikel ini bermaksud memberikan paparan tentang situasi dan kondisi Madinah saat ini ketika ibadah umrah itu dilaksanakan dan dengan begitu memaparkan bahwa Madinah 
sebagai tujuan ziarah dan ritual kaum Muslim tidak sesederhana yang dibayangkan hanya sebagai kota ibadah, tetapi Madinah merupakan kota yang sudah berkembang karena modernisasi dan globalisasi sehingga aktivitas tidak hanya terbatas ibadah. Aktivitas ekonomi dan bisnis, perhotelan, pertokoan, dan jual-beli, sangat dominan. Ibadah terkait erat dengan hal-hal duniawi dan tidak bisa dihindari dalam membahas ritual keagamaan mengaitkannya dengan kondisi sosial. ${ }^{3}$

\section{MADINAH DALAM SEJARAH}

Madinah adalah kota perdana dalam sejarah Islam yang dibangun langsung oleh Nabi Muhammad, setelah beliau hijrah (migrasi) dari Makkah, tempat kelahiran yang berstatus haram (suci). Pembangunan kota di abad tujuh Masehi dan pertama Hijriyah ini meliputi pembangunan politik dan agama; dalam hal ini, Islam berarti juga ritual, sosial, dan kekuatan politik. ${ }^{4}$ Di Madinah, masyarakat Muslim awal berkembang dan juga secara politik menguat, terutama setelah kemenangan demi kemenangan diraih dalam berbagai konflik dan peperangan melawan orang-orang Mekah dan non-Muslim sekitar. Sampai era empat khalifah pengganti pemimpin Nabi Muhammad (Abu Bakar, Umar, Utsman, dan Ali) yang tetap beribukota di Madinah, pusat politik lalu pindah ke Damaskus, lalu Baghdad, dari dinasti Umayyah dan Abbasiyah. Secara politik, perpindahan kekuasaan selanjutnya dalam sejarah Islam terjadi berkalikali dan berlainan negara, benua, dan belahan dunia. Namun, Madinah sebagai kota suci (haram) tetap penting dalam kehidupan keagamaan Muslim di seluruh dunia hingga kini. Madinah penting karena masjid Nabawi yang dibangun Nabi dan sudah diperluas meliputi rumah, makam, dan halaman, raudhah (tempat imam dan makam Nabi), makam Baqi (para sahabat dan muslim awal), bukit Uhud, masjid Quba, dan masjid Bain Qiblatain (antara dua kiblat), dan sekarang terdapat museum di samping Masjid Nabawi yang megah. ${ }^{5}$

Membayangkan Madinah pada era Nabi, dan sesudahnya pada masa kekhalifahan dan klasik tentu berbeda dengan Madinah modern saat ini. Tetapi letak sebagai sebuah haram dalam relijiusitas Muslim tidak banyak berubah, walaupun sesudah menghadapi berbagai perubahan sejarah dan politik. Tepatnya, Madinah terletak di propinsi Hijaz, kerajaan Saudi Arabia dengan letak geografis $24^{\circ} 28^{\prime} \mathrm{N}$, longitudinal 39³ $36^{\prime} \mathrm{E}, 160 \mathrm{~km}$ dari Laut Merah, dan sekitar 350 km dari kota Mekah, arah utara. ${ }^{6}$ Konon sebelum zaman Nabi bermigrasi, Madinah bernama Yatsrib dan nama itu masih banyak juga disebut dalam dokumen-dokumen sesudahnya. Penduduk sebelum masa Is- 
lam, didominasi suku-suku Arab berbagai klan dan juga sebagian penduduk menganut Yahudi, dan terjadi percampuran antara Yahudi dan Arab dalam hal budaya, tradisi, dan perkawinan. ${ }^{7}$ Beberapa suku Yahudi yang disebut dalam kitab sirah, tabaqat, dan tarikh, masih berafiliasi Yahudi dan berhadapan dengan Islam awal yang pesat dan terjadi konflik dan perjanjian dengan masyarakat Muslim awal, yang terekam dalam dokumen yang dikenal dengan nama Madinah Charter (Perjanjian Madinah).

Madinah sudah mengalami transformasi berkali-kali dari satu era ke era yang lain, satu dinasti ke dinasti yang lain, dan satu perubahan politik ke perubahan politik yang lain. Dari sisi fisik dan arsitektur tampaknya Madinah tidak meninggalkan satu bangunan kuno era Nabi pun, dan peninggalan yang signifikan, karena perubahan yang sangat mendasar terjadi era Wahabi modern awal, peralihan dari Turki Utsmani dan wangsa Saudi, di awal abad dua puluh. Konon tahun 1916, Syarif Husain b. Ali memberontak kekuasaan Turki di provinsi Hijaz, namun pemberontakan gagal, dan Hijaz tetap termasuk Madinah di tangan Turki. Namun setelah perang, Hijaz menjadi daerah kekuasaan Syarif Husain hingga tahun 1925. Rival utama Syarif Husain adalah Ibn Saud yang mengambil Hijaz tahun 1925 termasuk Madinah. ${ }^{8}$ Pada awal abad dua puluh Raja Abd. al-Aziz mengawali perubahan itu dan mengubah seluruh bangunan dan tempat-tempat sakral. Wahabi sangat mencurigai segala bentuk kesyirikan dan menghabisi seluruh situs sekitar rumah Nabi, makam Nabi dan para khalifah dan keluarganya yang saat ini dikenal dengan nama Raudah, dan makam-makam yang sekarang dikenal sebagai Baqi. ${ }^{9}$ Namun, sebagai kota tujuan ziarah dan ibadah, status suci Madinah tetap dipertahankan dengan alasan persaudaraan dan tentu saja ekonomi, karena kehidupan agrikultur tempo dulu sudah tidak dapat lagi menopang kota ini. Sejak berkembangnya industri minyak di Saudi, Madinah sudah resmi meninggalkan era agrikultur yang sejak masa Nabi masih dikenal dengan berbagai tanaman seperti kurma (phoenix dactylifera) dengan berbagai jenisnya, anggur (vitis vinifera), delima (punica granatum), tin (ficus carica), dan zaitun (olea europaea). Semua produk itu masih bisa dilihat di Madinah kini, namun sebagai penghasil utama dan penopang ekonomi Madinah, tidak lagi bisa diandalkan. Banyak produk itu dijual ditempat-tempat tertentu dan pasar, baik tradisional maupun mall-mall modern, namun hanya sebagai oleh-oleh peziarah. Pemerintah modern Saudi berinvestasi besar sekali dalam ekonomi infrastruktur dan superstruktur untuk keperluan ziarah ke dua kota suci (Mekah dan Madinah), dan itu terasa sekali hingga kini, bahwa ziarah telah dan akan 
menghidupi sekian banyak penduduk dua kota itu dalam jasa akomodasi, dagang, dan wisata religi. ${ }^{10}$

Pada masa awalnya, Madinah sebagai pusat pemerintahan Nabi dan juga pusat masyarakat Islam awal, Madinah penting dari berbagai segi sosial, politik, agama, dan budaya. Namun, sejak pemerintah Mu'awiyah b. Abi Sufyan pindah ke Damaskus dan dimulainya dinasti Umaiyah, Madinah menjadi kota yang sedikit netral dalam urusan politik, walaupun bukan berarti selamat dari konflik umat Islam yang berkepanjangan dan terus menerus. Sewaktu Mu'awiyah menunjuk anaknya, Yazid b. Mu'awiyah sebagai khalifah, banyak yang tidak setuju dan berlindung di Madinah. Mereka yang tidak ingin terlibat pertikaian demi pertikaian juga berada di Madinah seperti Abdullah b. Umar. Namun, masa itu juga sekaligus Madinah sebagai kota yang sedikit terisolasi dan terpisah dari hiruk-pikuk politik Damaskus dan Baghdad selanjutnya pada era Abbasiyah. Sampai pada masa Turki Utsmani, Madinah sepertinya hanya tempat beribadah, pengkajian dan diskusi keagamaan. Imam Malik menjadikan tradisi penduduk kota ini sebagai sumber hukum dan masuk dalam kategori "sunnah". Imam Syafi'i tidak menganggap ini penting dalam hal hukum Islam, dan lebih memilih Hadis, ijmak dan qiyas. Banyak ilmuwan, ulama, dan para ahli Islam awal tinggal di kota Madinah. Namun Madinah modern saat ini bukanlah Madinah ratusan tahun yang lalu. Madinah modern merupakan jawaban dan reaksi atas berkembangnya politik di Saudi yang dikuasai ideologi Wahabi dengan relijiusitas Muslim dunia serta keterikatan emosi orang beriman pada kota yang dibangun oleh Nabi ini.

Serjeant, ${ }^{11}$ salah satu pemerhati sejarah Islam awal, berasumsi bahwa status haram Madinah itu tidak sejak awal pra-Islam telah ada, tidak seperti Mekah yang memang sudah berstatus haram jauh hari sebelum Islam dan Qur'an diwahyukan. Haram pada dasarnya merujuk pada larangan bagi penduduk sekitar untuk melakukan perang antar suku, membunuh, menyakiti makhluk hidup, bahkan memotong rambut. Haram berhubungan dengan kedamaian dan aliansi antar suku. Suku dan kesukuan di Arab melibatkan banyak hal tentang kerjasama, perserikatan, pernikahan, dan perjanjian. ${ }^{12}$ Misalnya, suku yang lemah akan berlindung di Ka'bah di Mekah karena status haram itu, dan suku yang kuat melindunginya. ${ }^{13}$ Di Madinah, haram bermula dari perjanjian Madinah yang memuat pemberian kesalamatan bagi orang Muslim dan non-Muslim, maka status kota Madinah itu meningkat dari tempat migrasi dan tempat tinggal Nabi menjadi haram dan suci pada era itu dan sesudahnya. Patut dicatat pula, bahwa status haram sebetulnya 
terdapat pada banyak tempat, tidak hanya milik eksklusif kota Makkah, tetapi misalnya Yamamah juga berstatus haram, bagi pemimpin agama dan politik lain, yakni Musaylimah. ${ }^{14}$ Begitu juga beberapa suku pra-Islam mempunyai tempat suci yang diharamkan, dimuliakan, berfungsi sebagai tempat perdamaian, dan tempat ibadah. Non-Muslim tidak diperkenankan berkunjung ke dua kota haram (Mekah dan Madinah). ${ }^{15}$ Peters bahkan berteori bahwa status haram Madinah justru terbentuk setelah Nabi wafat, karena ada makam Nabi di sana, maka Madinah dimuliakan oleh umat Islam. ${ }^{16}$ Sebelum Nabi wafat, tidak ada tempat istimewa yang dimuliakan dan bisa mengangkat status haram Madinah. Status ini yang akhirnya menjadi daya tawar Madinah pada era-era selanjutnya setelah Nabi.

\section{HOTEL DAN MALL}

Setelah penulis tiba di kota Madinah pada tanggal 12 Maret 2016, berikut narasi yang bisa disusun berdasarkan observasi, pengalaman, dan wawancara. Madinah yang saat ini terlihat adalah kota metropolitan, yang penuh warna tidak hanya tentang religiusitas atau keislaman, tetapi juga menyangkut peran sosial dan ekonomi. Yang jelas melihat Madinah saat ini sudah menyangkut persoalan kapitalisme dan relijiusitas yang menyatu. Kota ini tidak hanya dihiasi masjid agung dan megah, masjid peninggalan Nabi Muhammad yang dibangun masa beliau masih memimpin masyarakat terbatas city-state Madinah, namun kini dihiasi oleh mall-mall dan hotel-hotel berbintang mengelilingi kota ini. Yang jelas mall terbesar tepat di sebelah masjid adalah al-Noor mall ${ }^{17}$ dan tempat belanja Ben Dawood, ${ }^{18}$ yang sangat lengkap seperti Carrefour di Indonesia yang menjamur; tempat belanja lengkap yang megah dan menjanjikan secara komersial yang mengundang banyak pengunjung dari masjid Madinah itu sendiri. Mall dan tempat belanja tersebut modern dan lengkap dari mode sampai jam tangan dengan produk-produk Barat dan China. Mall adalah entitas yang bisa diukur dengan kacamata ekonomi dan sosial, begitu juga mall di Madinah.

Di sekeliling Masjid Nabawi adalah hotel-hotel megah dan berbintang, tempat para peziarah menginap, lengkap dengan fasilitas yang memadai. Di antara yang megah dan berbintang lima dan empat: Crowne Plaza Madinah, Intercontinental Dar al-Iman, Intercontinental Dar al-Hijrah ${ }^{19}$, Madinah Hilton, Anwar al-Madinah Movenpick Hotel. ${ }^{20}$ Ada banyak website yang berisi informasi termasuk harga hotel di Madinah. ${ }^{21}$ Penulis sendiri sebagai peziarah pada rombongan umrah tinggal di salah satu hotel yang dekat dengan Masjid 
Nabawi, Safoora al-Huda yang berbintang empat dengan pelayanan yang baik. ${ }^{22}$ Teman saya Sumanto Al Qurtubi, yang bekerja sebagai professor di dekat kota Riyadh, yang kebetulan bertemu di Madinah, memilih tinggal di hotel Nozol, yang kurang lebih sama bintangnya dengan hotel saya. ${ }^{23}$ Hotel kami berdua dikelilingi hotel-hotel mewah menjulang dan berwibawa. Kami sebagai anggota peziarah umrah tidak memesan hotel sendiri karena disediakan oleh biro travel. Pemimpin rombongan Abu Syauqi, mempunyai hubungan dengan orang Indonesia yang menjadi pemukim di sana, dan disitulah peran orang ini menghubungkan biro travel di Indonesia dengan hotel dan segala persiapannya di Tanah Suci. Jelasnya, Abu Syauqi tidak membuka website hotel untuk memesan hotel secara mandiri, tetapi bertumpu pada kenalan orang Indonesia yang bermukim di Saudi. Mereka yang bermukim rata-rata berprofesi sebagai mediator dan terutama sebagai mutawwif, semacam tour guide, tetapi untuk umrah dan haji.

Walaupun identik dengan pemandangan hotel dan mall, tidak semua peziarah selalu berbelanja. Beberapa peziarah selalu berusaha tinggal di Masjid Nabawi, tidak pernah, atau jarang sekali menengok kamar hotel. Dari kegiatan hotel bisa kita mengintip: setiap pagi sarapan dengan model arab: khubz, buah zaitun olive, tahinah, susu dan keju Arab. Menu nasi ada dua: nasi putih dan nasi asin. Para peziarah yang tinggal di Sofara al-Huda berasal dari Malaysia, Singapura dan Indonesia yang selara makannya sama. Mereka memilih tahu, ikan bandeng dan rendang. Siang dan malam selera nusantara, lengkap dengan sambal, kerupuk, dan sayur lodeh. Makan di Madinah, walaupun terlihat seperti masakan Indonesia, tidak seperti di Indonesia, rasanya masih kurang berbumbu dan terasa seperti rasa Melayu, tetapi dipaksakan.

\section{PASAR TRADISIONAL}

Yang menarik dari pemandangan Madinah dan sekitarnya di samping pasar tradisional tidak kurang dari 200 meter dari masjid adalah banyaknya burung dara yang beterbangan. Para penjaja makanan burung dara juga bersemangat menawarkan pada para peziarah untuk memberi makan. Burung dara beterbangan di pasar tradisional tepat di muka Masjid Nabawi lurus. Patut dicatat, bahwa pasar tradisional ini semakin sedikit peminatnya, jika dibanding dengan toko-toko yang sudah modern di sekitar hotel dan Masjid, tentu fasilitas dan kenyamanan mengalahkan yang lebih kuno dan tradisional. Madinah adalah kota komersial, sepertin masa lalunya. Pusat perdagangan dan transit para jamaah umrah menjanjikan keuntungan yang tidak sedikit, maka para 
pedagang dan pemodal, baik itu tradisional maupun internasional sangat bersemangat untuk bersaing dan mengadu untung dengan menanam modal di kota suci ini.

Pasar tradisional masih menjual kurma kering, tasbih, turban, akar siwak (salvadora persica), dan produk-produk klasik yang biasa menjadi oleh-oleh peziarah ketika pulang. Yang unik dan patut dicatat adalah para penjaja menjual dengan mengucapkan beberapa bahasa Indonesia. Begitu saya dan istri datang menghampiri penjual itu, mereka menyapa dengan bahasa Indonesia, terutama tentang angka dan kosa kata kunci dalam perdagangan itu, "Cukup dua puluh real saja." Dilanjut dengan kata-kata lain, "Ini tiga puluh real. Itu seratus real saja. Murah, ini dijual murah." Juga di restoran Arab yang sangat laris dan berjubel pun menjual dengan bahasa Indonesia. Makanan khas Arab: ayam panggang, domba, dan terong, juga melayani bahasa Indonesia. Beberapa menerangkan dagangannya dengan bahasa Indonesia. Bahkan sedikit ada sentimen atau ikatan emosional, karena antri memakai bahasa Indonesia, yang antri lainnya dilewati. Pengaruh Melayu atau Nusantara tempo dulu dalam sejarah ${ }^{24}$ masih terasa di Madinah, apalagi di Mekah yang nantinya akan ditulis dalam artikel terpisah. Bahasa Indonesia atau Melayu cukup populer, para pedagang buah, emas, dan pakaian cukup fasih mengucapkan beberapa kata dasar seperti "Murah, dua puluh, empat puluh, sampai seratus." Salah satu toko kebun kurma di pinggiran Madinah, penjualnya memang orang Indonesia menggunakan bahasa Indonesia dengan pengeras suara. Penjual ini melengkapi iklannya untuk buah kering dari tin, kurma, plum (prunus), zaitun, dan lain-lain dengan menjanjikan bahwa itu tidak hanya makanan kesukaan Nabi, juga makanan di surga.

\section{KIOS-KIOS}

Di samping mall dan hotel, sekitar masjid Nabawi terdapat banyak kios beraneka rupa, mulai dari mainan anak-anak, parfum, pakaian, buah-buahan, hingga jam tangan. Yang patut dicatat adalah keragaman dari suasana perdagangan dan toko-toko modern dan semi-modern yang buka di sepanjang jalan sekitar hotel, dan kadang seperti pasar "kaget" di sekitar masjid, adalah produk yang cukup "Barat." Barang produk Eropa seperti jam tangan merk Swatch, Tag Hauer, Festina, Tissot, Rolex, dan merek-merek terkenal lainnya menjadi favorit. ${ }^{25}$ Tentu ini jauh dari unsur sekedar ibadah dalam mengunjungi masjid Nabawi dan Madinah kota Nabi membangun umat, namun ini hendaknya harus dilihat dari sisi etnografis yang melibatkan unsur sosial, 
ekonomi, politik, dan dalam konteks globalisasi masa kini. Salah satu bukti dari globalisasi dan pengaruh era ekonomi di luar kendali dan batas negara adalah produk-produk modern dari berbagai negara yang banyak mewarnai toko-toko di Madinah. Madinah tidak lagi tradisional dan hanya tempat ziarah dan ibadah untuk umrah ataupun haji, namun kota itu adalah kota perdagangan dan tempat produk-produk bersaing satu dengan lainnya, dengan begitu para peziarah tidak dianggap lagi hanya sebagai orang yang sekedar beribadah, tetapi sebagai konsumen yang menjanjikan potensi pasar dan profit. Pola pikir dan faktor seperti ini akan menempatkan Madinah tidak hanya sebagai tempat tujuan ziarah ibadah, namun juga sebagai pasar potensial, kapitalisasi; dan bahkan dengan tradisi oleh-oleh yang banyak dijumpai ketika haji dan umrah adalah jam tangan merek terkenal. Pemimpin rombongan umrah, Abu Syauqi, dengan bangga menunjukkan hadiah dari salah satu temannya dari Indonesia yang bermukim di Madinah, berupa jam tangan asli Tissot dari Swiss.

Toko-toko buah berjejeran, dan terutama kios semi modern lebih ramai. Para peziarah lebih nyaman mengunjungi yang semi modern dengan harga tertera di tag daripada yang tradisional dengan harga yang masih tawarmenawar. Di pasar tradisional, ditemui penjaga toko surban, sajadah, dan topi haji yang mengaku bolak-balik Jakarta-Madinah. Buah-buahan yang umum bisa dijumpai adalah izmir pig (tin) yang konon di suatu pasar tradisional, para peziarah menyatakan itu buah surga. Seorang peziarah dari rombongan umrah, bergumam kepada temannya, "Di surga nanti hidangannya adalah buah tin". Tidak tahu kebenarannya apakah di surga nanti akan menikmati buah tin, namun membeli barang di Madinah juga didasari keyakinan teologis akan berkah, bahwa tin adalah buah surga, kurma adalah makanan Nabi dan sahabatnya, makanan yang lebih berkah dan lebih salafi daripada makanan keseharian orang Indonesia: beras dan umbi-umbian. Terdapat peziarah di rombongan kami yang sudah berulang-ulang datang ke Madinah dengan sengaja mencari jenis kurma tertentu. Pemimpin rombongan, Abu Syauqi mencari kurma jenis sukkari: hitam bulat dan dengan harga terjangkau. Hematnya, kurma itu cukup manis dan berkualitas, dengan khasiatnya tidak hanya sebagai obat segala macam penyakit, juga sebagai obat kuat dalam aktivitas seksual. Abu Syauqi menerangkan itu kepada penulis sembari tersenyum yang disambut gelak tawa seluruh peserta umrah di bus yang disopiri oleh orang Indonesia yagn sudah lama bekerja di Madinah. Kebiasaan umrah berkali-kali merupakan tradisi baru masyarakat Indonesia, 
karena ekonomi meningkat, dan transportasi pesawat yang terjangkau. Biro umrah juga bermunculan bak cendana di musim hujan. Mereka meraup untung dan terus menjalankan bisnis dengan persaingan yang ketat. Konon masyarakat Madura kelas atas, yaitu kelas kiai, menjalankan umrah berkalikali dengan tujuan untuk berbulan madu. Dalam tradisi Madura, banyak kiai, atau minimal keluarga kiai, yang berpoligami berkali-kali dan berbulan madu di Tanah Suci dengan melaksanakan umrah. Salah satu informan adalah Emma, berasal dan masih keluarga kiai di Madura yang menyaksikan para saudara dan tetangga sesama kiai melakukan poligami dan berbulan madu dengan menjalankan umrah. Dalam melaksanakan umrah untuk berbulan madu, kemungkinan kurma jenis sukkari yang dipercaya meningkatkan libido seksual, menunjang kelas elit itu untuk menikmati ibadah dan istri baru sekaligus.

\section{MASJID NABAWI}

Madinah saat ini, pada abad 21, adalah kota metropolitan dan modern. Jalanan rapi dan hotel-hotel mendominasi pemandangan kota. Hotel-hotel menjulang tinggi dengan arsitektur terkini dengan fasilitas lengkap dan berbintang. Jauh dari kesan padang pasir dan kuno tempat perang antar suku, Madinah kini tidak hanya kota tradisional tujuan ziarah dan ibadah. Memang selama dua puluh empat jam, masjid Nabawi yang megah selalu ramai dengan para pengunjung yang beribadah, berfoto selfie, dan beraktivitas jual beli. Para peziarah biasanya menenteng tas kecil untuk membawa sandalnya ke dalam masjid, karena kalau diletakkan di depan masjid kemungkinan akan hilang. Masjid Nabawi sejak dari pelataran sampai area dalam memang luas dan mewah, dengan tiang-tiang berjajar, penuh ukiran kaligrafi indah menawan. Lantai marmer dari bebagai benua mengkilap tertutupi karpet rapi dan bersih, dengan warna mencolok licin. Tiang-tiang membentuk batang kurma dan pelepahnya mengembang, seperti di kebun kurma era Nabi yang duduk dengan para sahabatnya seribu empat ratus tahun lalu. Sekilas tiangtiang kuno di dalamnya terlihat seperti tiang-tiang terkenal Masjid Granada di Spanyol Eropa di masa kejayaan Islam dinasti Umaiyah. Bedanya, Masjid Nabawi masih aktif dan terus menerima tamu dari para peziarah seluruh dunia dengan berbagai macam pakaian, gaya, ritual, niat, dan aktivitas. Masjid Nabawi dipenuhi para peziarah tidak pernah berhenti dan selalu ramai: duduk berdoa, berdiri shalat, minum air zamzam di sepanjang tiang, dan membaca Qur'an. Setiap waktu shalat, para jamaah berebut untuk maju dan duduk di shaf terdepan. Di sekitar tiang masjid, air zamzam ditempatkan di wadah- 
wadah dengan pancuran gratis diminum.

Bentuk arsitek Masjid Nabawi pada dasarnya mengambil inspirasi dari pohon kurma, yang sudah terkenal sejak masa Nabi. Madinah memang lebih subur dari Mekah, karena banyak sekali kebun kurma sampai kini. Tiangtiang megah mengitari seluruh kompleks Masjid Nabawi dengan mengambil motif kurma, mengembang, menyangga atap yang kokoh. Petugas kebersihan berkeliling dengan membawa sapu, juga petugas shaf dan seperti polisi yang memakai turban khas Arab, putih dengan kotak-kotak merah kecil. Setiap sudut terdapat al- Qur'an yang dipajang di dekat tiang-tiang rapat, juga air zamzam gratis. Para jamaah yang berjubelan dapat meminumnya, sebagian berkonsentrasi membaca Qur'an atau sedang berdoa berkomat-kamit. Di luar masjid, lebih tampak motif kurmanya. Pelataran Masjid Nabawi dihiasi payungpayung yang mengembang saat diperlukan, siang dan hujan. Payung menutup saat siang. Pelataran masjid menegaskan kembali, bahwa kurma merupakan ide dasarnya. Payung menutup bermotif pohon kurma sangat jelas; jika mengembang berubah seperti payung besar melindungai para peziarah yang sedang berdoa, seperti zaman kuno dahulu, ketika para sahabat Nabi berkumpul di area itu, di bawah pohon kurma.

\section{PARA PEZIARAH}

Para jamaah yang sekaligus peziarah ke kota Madinah sangat beragam. Berbagai rasa dan tradisi keagamaan bisa dilihatnya, dari cara beribadah dan jenis pakaian yang tampak. ${ }^{26}$ Yang asli dari tanah Arab berpakaian ala Saudi menggunakan turban putih bermotif merah dan berbaju putih. Namun kebanyakan para peziarah yang berasal dari belahan dunia lain menggunakan pakaian tradisional masing-masing, yang berbeda dan kadang mencolok. Peziarah Pakistan menggunakan pakaian Pakistan yang lain sama sekali dengan tradisi berpakaian Arab. Peziarah India menggunakan pakaian India yang menjuntai. Dari Eropa Timur bekas daerah Soviet juga banyak sekali menampilkan pakaiannya yang khas. Dari Indonesia, Singapura dan Malaysia menggunakan pakaian Asia yang khas dengan sarung dan songkok hitam, dan kadang dikombinasi dengan topi bulat putih, atau dikenal dengan istilah topi haji.

Madinah adalah kota beragam yang sama sekali tidak seragam. Dari sisi peziarah, ini meliputi orang-orang Muslim dunia yang plural. Dari etnis dan tradisi keagamaan, Islam tidak satu, tapi kompleks dan jumlahnya beraneka rupa. Banyak kebiasaan yang tidak kita ketahui. Dari segi tutup kepala banyak 
yang memakai topi beragam, Indonesia sendiri mempunyai banyak ragam topi, dari kopiah tradisional hitam, sampai putih bulat yang sekarang umum dipakai. Songkok putih pun dengan hiasan bunga-bunga atau motif indah lainnya yang menjadikannya berbeda dengan topi bentuk lain. Banyak Muslim dari India, Afrika, Pakistan atau Eropa Timur yang memakai topi model lain dan bertambah beraneka rupa bagaimana para jamaah berbeda antara satu dan lainnya. Topi kecil seperti topi Yahudi dipakai oleh orang Eropa Timur, dengan lobang di depannya untuk sujud. Surban dilipat-lipat dilingkarkan di kepala, bahkan bagaimana melipatkannya bermacam-macam cara, belum juga menyebut jenis surban, warna, dan model yang digunakan oleh orang dari berbagai tradisi dan budaya. Kreatifitas orang beriman dalam memakai pakaian menunjukkan bahwa agama Islam yang telah menyatu dengan budaya selalu hidup dan tidak mati. Interpretasi pakaian selalu seiring dengan budaya dan tradisi setempat, dan kini berkumpul di Madinah untuk tujuan ziarah dan mengenang bagaimana Madinah seribu lima ratus tahun yang lalu.

Ada upaya homogenisasi misalnya dengan pakaian ala Arab, dan ini terlihat di Indonesia itu sendiri, yang mungkin lebih terasa lebih Islami dengan adopsi budaya Arab yang serba menjuntai dan bersurban. Tetapi sentuhan dari masingmasing baju Arab dari berbagai belahan dunia menampakkan perbedaan yang menyolok dan tidak mengarah pada penyeragaman. Kreatifitas menggabungkan berbagai tradisi dan saling menginspirasi atau saling meniru dan mempengaruhi, menambah heterogennya Islam dilihat dari sisi mode dan gaya. Fenomena para peziarah di Madinah menunjukkan, bahwa Islam tidak satu dan homogen. Sejak awal tidak mungkin Islam disamaratakan dalam tradisi dan budaya. Islam memang mengajarkan persamaan, ekualisisasi dan egalitarianism, namun bukan berarti homogenisasi. Tradisi Islam awal agama ini mengajarkan persamaan pada manusia karena semua ras berkedudukan sama di mata Tuhan, tetapi tidak menyeragamkan budaya (Q.S. 49: 13). Ras dan kultur yang berbeda memberikan sentuhan berbeda dan beragam pada Islam itu sendiri. Ini terlihat di Madinah, tempat penting berkumpulnya umat Muslim dari seluruh dunia. Jauh sekali dari kesan seragam pada para peziarah, tetapi berbeda-beda dan satu; dan ini semua memperkaya unsur Islam global saat ini.

Para peziarah kota Madinah tetap rapi. Mereka tinggal di hotel-hotel mewah di sekitar masjid Nabawi, makan dan bertempat tinggal dengan jadwal yang teratur dibimbing mutawwif. Setiap waktu shalat, mereka pergi ke masjid Nabawi dengan berjalan. Mobil-mobil berhenti memberi jalan para peziarah 
menuju masjid Nabawi. Shalat subuh dengan azan dua kali; yang pertama sebagai penanda untuk pergi ke masjid, yang kedua penanda waktu shalat subuh. Jamaah sudah mulai berdatangan sekitar jam tiga malam, bahkan ada yang sengaja bermalam di masjid itu untuk i'tikaf. Para peziarah dari travel dibangunkan pada hari pertama untuk mengikuti shalat pertama qiyamul lail di masjid Nabawi.

\section{MUSEUM}

Di samping Masjid Nabawi dibangun museum, namun akan sedikit mengecewakan karena tidak secuil barang kuno era masa lalu pun yang tersimpan di museum itu. Pameran dalam museum itu lebih menyerupai rekaan maket dan rekayasa masa lalu daripada museum untuk menghadirkan masa lalu itu sendiri. Museum itu memperlihatkan biografi Nabi Muhammad yang tidak dilihat dari sumber-sumber terkuno yang mendekati era Nabi, tetapi dari buku-buku modern yang terbit di Arab era kini. Museum itu jelasnya merakayasa biografi era masa lampau, tetapi tidak berdasarkan data primer, temuan arkeologi, atau pun penelitian serius. Tapi lebih mencerminkan pada makna biografi demi religiusitas umat Muslim saat ini, berupa legitimasi keyakinan orang masa kini pada Nabi; citra yang dibentuk berdasarkan keimanan, bukan berdasarkan penelitian atau benda kuno. Bentuk rumah Nabi, bagan keturunan (nasab atau genealogi), kota Madinah masa itu, hanya berupa rekaan, tidak didukung barang-barang kuno yang pernah ditemukan: perisai, pedang, teks, atau barang-barang peninggalan. Citra Nabi diambil dari buku-buku terkini dan mungkin pembentukan baru siapa itu Nabi dan makna apa yang terkandung dalam Islam tempo ini. Maket kuno tentang rumah Nabi dan Masjid Nabawi juga tidak dilengkapi dengan data dan penelitian historis yang memadahi. Tetapi museum merupakan rekayasa keimanan dan apologetis. Museum Madinah itu lebih bisa disebut sebagai sarana dakwah dan propaganda, daripada sarana sejarah dan tidak untuk menjawab bagaimana menghadirkan masa lalu sebenarnya. Semua yang dipamerkan sudah bernada teologis dan apologetis, untuk mengagungkan dan menarik minat para peziarah yang sudah dipenuhi dengan niat ibadah menggebu dan guna mencari berkah.

\section{KOTA KEDUA}

Tanda yang paling nyata di Masjid Nabawi Madinah adalah tulisan besar di pintu, "al-shalat fi hadha al-masjid afdhalu min alfi shalat illa fi masjid al- 
haram" (salat di masjid ini lebih mulia dari seribu kali [di masjid lain] kecuali di Masjid al-Haram). Deklarasi yang sekaligus pernyataan, bahwa status Madinah sebagai kota Nabi, pembangun kota ini dan peletak dasar masyarakat Madinah, kota tempat Nabi membangun umat Islam, komunitas pertama yang menjadi pusat dua hal: pemerintahan berupa kota Madinah itu sendiri yang diteruskan sampai empat khalifah (Abu Bakar, Umar, Utsman dan Ali), berupa city-state, sebagaimana disebutkan dalam Republic-nya Plato seribu tahun sebelumnya, ${ }^{27}$ juga sebagai pusat agama, yaitu Vatikan Romawi yang telah ada paling tidak tiga ratus tahun sebelumnya.

Madinah adalah dua hal, dimana politik dan agama menyatu saat zaman Nabi itu sendiri. Namun, dari sisi kutipan kaligrafi di Masjid Nabi di atas, jelas bahwa awalnya Nabi tidak membangun sanctuary-shrine (tempat suci) di Madinah, jika itu masih relevan adanya, tidak ada perubahan pada masamasa selanjutnya. Madinah tetap di bawah Mekah dengan statusnya secara keagamaan dan kesakralan, sebagai tempat dimana Nabi dan kaum Quraisy berasal dan menjaga Ka'bah. Suku Quraisy adalah penanggung jawab atas Ka'bah sebagai tempat yang dimuliakan, bahkan sebelum Islam. ${ }^{28} \mathrm{Ka}$ 'bah merupakan simbol utama dari umat Islam hingga kini. Madinah kota kedua, setelah Mekah, dalam arti relijiusitas bagi Muslim seluruh dunia. Nabi yang sudah pindah ke Madinah karena menerima tantangan dan perlawanan kaum status quo di Mekah masih saja menempatkan ritual utama mengarah ke Mekah, arah kiblat shalat.

Kiblat Madinah dari dahulu hingga kini tetap saja Mekah. Walaupun dulu kala masyarakat Madinah pernah berkiblat ke Jerusalem, Bait al-Maqdis, ${ }^{29}$ yang pada masa Umar khalifah kedua dibangun al-Aqsa. Hal itu dibuktikan dengan masjid Bain Qiblatain yang masih berdiri dan shalat pernah dilakukan dengan menghadap ke dua arah kiblat, Bait al-Maqdis dan Ka'bah. Nabi lalu diperintahkan Tuhan untuk memilih Mekah sebagai awal dan penanda identitas Islam yang berbeda dengan Yahudi dan Kristiani, yang sama sekali tidak ada relasinya secara teologis dengan Mekah. Madinah sebagai kota hijrah mempunyai status yang unik, pusat pemerintahan dan pusat agama, dimana Nabi diturunkan padanya banyak ayat Qur'an.

\section{RAUDHAH}

Tempat yang paling suci di Madinah selain masjid sebagai magnet yang menarik kaum Muslim adalah raudhah: tempat imam dan makam Nabi, Umar dan Abu Bakar. Juga sekaligus rumah Nabi dalu, yang tidak terlihat lagi, 
karena konon dihancurkan demi pembangunan dan perluasan Masjid yang hingga kini tidak pernah berhenti. Untuk ke raudhah, peziarah harus masuk Masjid Nabawi melewati tempat imam. Antrian padat dan sangat kompetitif, penuh dengan orang-orang dari berbagai penjuru dan terlihat dari pakaian dan bahasa yang digunakan. Antrian panjang dari subuh hingga subuh berikutnya menandakan kekeramatan tempat ini. Masjid Nabawi tidak pernah mati dan istirahat, juga karena faktor raudhah. Untuk masuk di dalamnya yang banyak dipenuhi oleh ayat Qur'an dan keutamaaan Nabi, peziarah bersaing dan berdesakan dengan bersemangat satu dengan lainnya. Shaf (barisan) demi shaf terlalui dengan kesabaran dan himpitan peziarah, akhirnya penulis berhasil masuk di raudhah. Tulisan Arab indah mengantung di sana sini, tembok dan ukiran, dengan berbagai ayat Qur'an. Setelah mencapainya, para peziarah bersemangat untuk salat beberapa rakaat. Waktu penulis berhasil mencapai raudhah dengan perjuangan adalah dhuha, segera penulis melaksanakan salat beberapa rakaat, sebagaimana pemimpin rombongan Abu Syauqi mencontohkannya. Shalat dhuha itu dilaksanakan berkali-kali dan setelah usai harus segera pergi karena bergiliran dengan peziarah lainnya. Petugas askar (polisi) akan mengusir peziarah yang sudah terlalu lama. Selanjutnya para peziarah berjalan menyusuri makam Nabi dan dua sahabat utama yang terlihat dari lubang kecil, itupun dijaga ketat oleh askar.

Seorang peziarah dari India dengan bahasa Inggris khas logat India berdiri antri di belakang penulis. la bersemangat, tersenyum dan menyapa, "You are from Indonesia, right?". Penulis balik bertanya, "How do you know?". la tersenyum dan menunjuk, "Your black hat is typical dan indeed pretty". Peziarah ini terus membaca Qura'n diiringi zikir sepanjang antrian. la sangat berharap agar bisa masuk Raudah, sebagaimana juga jamaah di samping penulis, dari Pakistan, Afrika, Eropa Timur, dan lain-lain. Di samping penulis juga terdapat tiga anak muda dari Mesir berbahasa Arab, kemudian penulis sapa dengan Arab fusha (resmi), "Min ain?". Tiga orang Mesir ini tersenyum sambil berdesakan, "Min Indonesia tahki bi al-fusha." Dalam antrian berdesakan dan berhimpitan dengan kaki tetangga, penulis berusaha ramah dengan para pesaing. Berbincang soal logat fusha dan syuqiah (keseharian) dengan tiga pemuda Mesir untuk menghibur waktu. Untuk beberapa lama, penulis beradaptasi bahasa, agar tidak terlalu fusha. Seperti laisa diganti ma fi dan ghairu maujud juga dengan ma fi. Begitu juga di luar masjid ketika berjalanjalan, penulis bertanya pada para pedagang dengan bahasa yang sedikit gaya syauqi walaupun masih formal: "Kam tsaman!". Dia malah menjawab dengan 
bahasa Indonesia Melayu, "Dua puluh riyal saja, murah!". Penjagaan ketat bertujuan agar para pezirah tidak terlalu mendekat, mengusap pun tidak sempat. Hanya lewat sebentar dan memegang pintu dan lubang kecil untuk mengintip makam Nabi. Tapi banyak dari para peziarah yang sudah terharu luar biasa dan menangis sesenggukan. Seorang peziarah dari Surabaya, bertanya kepada penulis, "Apakah itu makam Nabi Muhammad." Penulis jawab: "Ya, betul." Langsung peziarah itu menangis, terharu, dan bergumam terbata-bata, "Ya Allah, saya akhirnya melihat makam Nabi Muhammad."

\section{KESIMPULAN}

Madinah sebagai kota Nabi dan tujuan ziarah kaum Muslim dunia hingga kini bukanlah semata-mata kota tempat ibadah dan ritual kekhusukan. Madinah sebagai kota yang berkembang terutama dalam menyambut para peziarah dunia yang tidak pernah sepi berkembang menjadi kota yang didominasi dengan aktivitas ekonomi dan sosial. Dan para peziarah dengan motivasi ibadah terus-menerus melakukan ritual. Namun di sekitar Madinah sebagai tempat bisnis dan penanaman modal meliputi hotel, mall, pertokoan, kios, dan pasar tradisional, merupakan tempat aktivitas ekonomi dan menjanjikan keuntungan. Dari sinilah nafas kapitalisasi kota itu muncul dan berkembang. Hotel mewah, mall, toko modern, sedang menggeser pasar tradisional dan toko kuno. Madinah yang sejak awal menjadi pusat ibadah dan negara Islam, telah bergeser dan berganti, terutama saat ini, peran ekonomi diwakili perhotelan dan mall sangatlah penting. Singkatnya, semangat keagamaan menyatu dengan semangat kapitalisme, beribadah dan berbisnis bagi mereka yang menanam modal. Kesimpulan lain ialah, bahwa ibadah di Madinah dengan berziarah sekaligus, menunjukkan keragaman pengunjung dengan berbagai mode, busana, gaya, budaya dan tradisi. Madinah adalah simbol keragaman karena banyaknya peziarah dari belahan dunia dengan praktik Islam yang berbeda. Di sisi lain, perkembangan kapitalisasi kota modern ternyata juga tidak menggeser semangat relijiusitas peziarah Madinah. Tampaknya, keagamaan saat ini menyatu dengan kapitalisme dan terlihat di kota Nabi.

\section{CATATAN AKHIR}

1 Lihat contoh penelitian etnografis, misalnya: Clifford Geertz, The Interpretation of Cultures: Selected Essays (New York: Basic Books, 1973); Robert W. Hefner, Hindu Javanese: Tengger Tradition and Islam (Princeton, N.J.: Princeton Univer- 
sity Press, 1985); Al Makin, Challenging Islamic Orthodoxy: Accounts of Lia Eden and Other Prophets in Indonesia (Dordrecht, Holland; Cinnaminson [N.J.], U.S.A.: Springer, 2016).

2 Biro Haji dan Umrah Darul Hijrah Tour and Travel, "Album Kenangan Umrah 12 - 21 Maret 2016” (Darul Hijrah Tour and Travel, 2016).

3 Al Makin, Anti-kesempurnaan: Membaca, Melihat, dan Bertutur Tentang Islam (Yogyakarta: Pustaka Pelajar, 2002).

4 W. Montgomery Watt, Muhammad: Prophet and Statesman (London: Oxford University Press, 1961); W. Montgomery Watt, Muhammad at Medina (Oxford: Clarendon Press, 1956); Hugh Kennedy, The Prophet and the Age of the Caliphates: The Islamic Near East from the Sixth to the Eleventh Century (London; New York: Longman, 1986); Patricia Crone and Michael Cook, Hagarism: The Making of the Islamic World (Cambridge; New York: Cambridge University Press, 1977).

5 Muhòammad Farid Wajdi, Da'irah al-Ma»arif al-Qarn al-»Isyrin., vol. 8 (Beirut: Dar al-Fikr, 1996), pp. 542-552.

6 W. Montgomery Watt, "Al-Madinah," in The Encyclopaedia of Islam, ed. C Edmund Bosworth et al., vol. V (Leiden: Brill, 1986), pp. 994-98.

7 Wajdi, Da'irah al-Ma»arif al-Qarn al-»Isyrin., vol 8: pp. 529-542.

8 F E Peters, "Medina," in The Oxford Encyclopedia of the Modern Islamic World, ed. John L Esposito, vol. 3 (New York: Oxford University Press, 1995), pp. 92-93.

9 R. B. Winder, "Al-Madinah: Modern City," in The Encyclopaedia of Islam, ed. C Edmund Bosworth et al., vol. V (Leiden: Brill, 1986), pp. 998-1007.

10 Russel King, "The pilgrimage to Mecca: some geographical and historical aspects," erd ERDKUNDE 26, No. 1 (1972): pp. 6 1-73.

11 R. B. Serjeant, "Haram and Hawtah," in The Encyclopedia of Religion, ed. Mircea Eliade, vol. 6 (New York: Macmillan, 1987), pp. 196-98.

12 Ella Landau-Tasseron, "The Status of Allies in Pre-Islamic and Early Islamic Arabian Society,” Islamic Law and Society 13, No. 1 (2006): 6-32; Uri Rubin, "The Ilaf of Quraysh: A Study of Sura CVI," Arabica 31, no. 2 (1984): pp. 16588.

13 Lihat, misalnya, M. J. Kister, "Mecca and Tamim (Aspects of Their Relations)," Journal of The Economic and Social History of The Orient 8, no. 2 (1965): 113-63, doi:10.2307/3595962; M. J. Kister, "Some Reports Concerning Mecca from Jahiliyya to Islam," Journal of the Economic and Social History of The Orient 15, no. 1/2 (1972): 61-93, doi:10.2307/3596312.

14 Al Makin, Representing the Enemy: Musaylima in Muslim Literature (Frankfurt am Main; New York: Peter Lang, 2010); Al Makin, "From Musaylima to the Kharijite Najdiyya,” Al-Jami'ah 51, No. 1 (2013): pp. 33-60.

15 Zachary Karabell, "Medina," in Encyclopedia of The Modern Middle East, ed. Reeva S Simon, Philip Mattar, and Richard W Bulliet, Vol. 3 (New York: Macmillan Reference USA, 1996), p. 1192.

16 Peters, "Medina"; Soad Maher Muhammed, "The Kingdom of Saudi Arabia, Center of Islamic Civilization," in Saudi Arabia and Its Place in the World., ed. 
Ministry of Information, Kingdom of Saudi Arabia (Lausanne, Switzerland: Three Continents Publishers, 1979), pp. 77-100. “Al Noor Mall," diakses 6 Mei 2016, http://www.alnoormall.com/.

18 "Weekly Promotion Madinah," diakses 6 Mei 2016, http://www.bindawood.com/en/pro_madinah.html.

19 "Hotels Near Al-Masjid Al-Nabawi," IHG, akses 28 April 2016, http:// www.ihg.com/destinations/us/en/attractions/843-al-masjid-al-nabawimadinah-hotels.

20 "Good Hotel close to the Prophet's Mosque - Review of Elaf Taiba Hotel, Medina, Saudi Arabia - TripAdvisor,” akses 28 April 2016, https:// www.tripadvisor.com/ShowUserReviews-g298551-d306560-r105249399. Elaf_Taiba_Hotel-Medina_Al_Madinah_Province.html.

21 "Medina Hotels," akses 28 April 2016, https://www.expedia.co.id/ProphetsMosque-Hotels.0-16118152-0.Travel-Guide-Filter-Hotels?rfrr=Redirect.From.www.expedia.com\%2FProphets-Mosque-Hotels.0-16118152-0.TravelGuide-Filter-Hotels\&; "Hotels.com,” akses 28 April 2016, http:// www.hotels.com/de1684985/hotels-near-prophet-s-mosque-medina-saudiarabia/; "Hotel Dekat Al-Masjid Al-Nabawi - TARIF HOTEL TERBAIK Yang Berada Di Sekitar Tempat Ibadah Di Medina, Arab Saudi,” Agoda, akses 28 April 2016, http://www.agoda.com/id-id/hotels-near-al-masjid-al-nabawi/attractions/medina-sa.html; "Hotels near The Prophet's Mosque, Saudi Arabia.," Booking.com, akses 28 April 2016, http://www.booking.com/landmark/sa/themosque-of-the-prophet-mohammad.en-gb.html.

22 "Help! Which Hotel Is Best?," Booking.com, akses 30 April 2016, http:// www.booking.com/searchresults.en-gb.html?dest_id=-3092186;dest_type=city.

23 "Nozol Royal Inn Hotel, Al Madinah, Saudi Arabia," Booking.com, akses 30 April 2016, http://www.booking.com/hotel/sa/royal-inn.en-gb.html.

24 Michael Francis Laffan, Islamic Nationhood and Colonial Indonesia: The Umma below the Winds (London; New York: Routledge Curzon, 2003).

25 “OMEGA Watches: Al-Hussaini Trading Co, Medinah, Saudi Arabia," akses 6 Mei 2016, http://www.omegawatches.com/stores/storedetails/1407/; "RAYMOND WEIL Genève > Search > Swiss Luxury Watches," akses 6 Mei 2016, http://www.raymond-weil.com/en/stores/search; "TAG Heuer Store Madina - Luxury Watches in Madina - Paris Gallery Rashid Madina,” akses 6 Mei 2016, http://store.tagheuer.com/143329-paris-gallery-rashid-madina.

26 Untuk argumen keragaman, lihat, misalnya Al Makin, Keragaman dan Perbedaan, Budaya dan Agama Dalam Lintas Sejarah Manusia (Yogyakarta: Suka Press, 2016).

27 Plato, The Republic, ed. G. R. F Ferrari, trans. Tom Griffith (Cambridge: New York: Cambridge University Press, 2000).

28 Kister, "Mecca and Tamim (Aspects of Their Relations)"; Kister, "Some Reports Concerning Mecca from Jahiliyya to Islam”; Rubin, "The Ilaf of Quraysh"; Landau-Tasseron, "The Status of Allies in Pre-Islamic and Early Islamic Arabian Society."

29 al-Tabari, The History of Al-Tabari: The Foundation of the Community, ed. W. Mont- 
gomery Watt, trans. M. V McDonald (Albany, N.Y.: State University of New York Press, 1987), pp. 24-25, http://search.ebscohost.com/ login.aspx?direct=true $\&$ scope $=\operatorname{site} \& d b=$ lebk $\& d b=$ nlabk $\& A N=14037$.

\section{DAFTAR PUSTAKA}

Crone, Patricia, and Cook, Michael. 1977. Hagarism: The Making of the Islamic World. Cambridge-New York: Cambridge University Press.

Geertz, Clifford. 1973. The Interpretation of Cultures: Selected Essays. New York: Basic Books.

Hefner, Robert W. 1985. Hindu Javanese: Tengger Tradition and Islam. Princeton, N.J.: Princeton University Press.

Karabell, Zachary. 1996. "Medina." In Encyclopedia of the Modern Middle East, edited by Reeva S Simon, Philip Mattar, and Richard W Bulliet, 3:1192. New York: Macmillan Reference USA.

Kennedy, Hugh. 1986. The Prophet and the Age of the Caliphates: The Islamic Near East from the Sixth to the Eleventh Century. London-New York: Longman.

King, Russel. 1972. "The pilgrimage to Mecca: some geographical and historical aspects.” erd ERDKUNDE 26, no. 1: 61-73.

Kister, M. J. 1965. "Mecca and Tamim (Aspects of Their Relations)." Journal of the Economic and Social History of the Orient8, no. 2. h. 113-63. doi:10.2307/ 3595962.

Kister, M. J. 1972. "Some Reports Concerning Mecca from Jahiliyya to Islam.” Journal of the Economic and Social History of the Orient 15, no. 1/2: 61-93. doi: $10.2307 / 3596312$.

Laffan, Michael Francis. 2003. Islamic Nationhood and Colonial Indonesia: The Umma below the Winds. London: New York: RoutledgeCurzon.

Landau-Tasseron, Ella. 2006. "The Status ofAllies in Pre-Islamic and Early Islamic Arabian Society." Islamic Law and Society 13, no. 1: 6-32.

Makin, Al. 2002. Anti-kesempurnaan: Membaca, Melihat, danBertutur Tentang Islam. Yogyakarta: Pustaka Pelajar.

Makin, Al. 2016. Challenging Islamic Orthodoxy: Accounts ofLiaEden and Other Prophets in Indonesia. Dordrecht, Holland: Cinnaminson [N.J.], U.S.A.: Springer,

Makin, Al. 2013. "From Musaylima to the KharijiteNajdiyya." AlJami'ah 51, no. 1. h. 33-60.

Makin, Al. 2016. Keragaman Dan Perbedaan, Budaya Dan Agama Dalam Lintas Sejarah Manusia. Yogyakarta: Suka Press.

Makin, Al. 2010. Representing the Enemy: Musaylama in Muslim Literature. Frankfurt am Main. New York: Peter Lang.

Muhammed, Soad Maher. 1979. "The Kingdom of Saudi Arabia, Center of Islamic Civilization." In Saudi Arabia and Its Place in the World., edited by Ministry of Information, Kingdom of Saudi Arabia, 77-100. Lausanne, Switzerland: Three Continents Publishers.

Peters, F E. 1995. "Medina." In The Oxford Encyclopedia of the Modern Islamic World, edited by John L Esposito, 3:92-93. New York: Oxford University Press. 
Plato. 2000. The republic. Edited by G. R. F Ferrari. Translated by Tom Griffith. Cambridge, New York: Cambridge University Press.

Rubin, Uri. 1984. “The Ilafof Quraysh: A Study of Sura CVI.” Arabica 31, no 2: $165-88$.

Serjeant, R B. 1987. "Haram and Hawtah." In The Encyclopedia of Religion, edited by MirceaEliade, 6:196-98. New York: Macmillan.

Tabari. 1987. The History of Al-Tabari: The Foundation of the Community. Edited by W. Montgomery Watt. Translated by M, V McDonald. Albany, N.Y.: State University of New York Press.

Wajdi, Muhammad Farid. 1996. Da»irahma»arif al-qarn al-»ishrin. Vol, 8. Beirut: Dar al-Fikr.

Watt, W. Montgomery. 1986. "Al-Madinah.” In The Encyclopaedia of Islam, edited by C. Edmund Bosworth, van Donzel, Bernard Lewis, and Ch. Pellat, V:99498. Leiden: Brill.

Watt, W. Montgomery. 1956. Muhammad at Medina. Oxford: Clarendon Press.

Watt, W. Montgomery. 1961. Muhammad: Prophet andStatesman. London: Oxford University Press.

Biro Haji dan Umrah Darul Hijrah Tour and Travel. Album Kenangan Umrah 12 21 Maret 2016. Darul Hijrah Tour and Travel.

"Good Hotel close to the Prophet's Mosque - Review of ElafTaiba Hotel, Medina, Saudi Arabia - TripAdvisor.” akses28 April 2016. https://www.tripadvisor.com/ ShowUserReviews-g298551-d306560-r105249399-Elaf_Taiba_HotelMedina_Al_Madinah_Province.html.

"Help! Which Hotel Is Best?” Booking.com. akses 30 April 2016. http:// www.booking.com/searchresults.en-gb.html?dest_id=-3092186; dest_type=city.

"Hotel Dekat Al-Masjid Al-Nabawi - TARIF HOTEL TERBAIK Yang Berada Di SekitarTempatIbadahDi Medina, Arab Saudi.” Agoda. 28April 2016. http:// www.agoda.com/id-id/hotels-near-al-masjid-al-nabawi/attractions/medinasa.html.

"Hotels NearAl-Masjid Al-Nabawi." IHG. akses28 April 2016. http://www.ihg.com/ destinations/us/en/attractions/843-al-masjid-al-nabawi-madinah-hotels.

"Hotels nearThe Prophet's Mosque, Saudi Arabia." Booking.com. akses28 April 2016. http://www.booking.com/landmark/sa/the-mosque-of-the-prophetmohammad.en-gb.html.

“Hotels.com." akses28 April 2016. http://www.hotels.com/de1684985/hotels-nearprophet-s-mosque-medina-saudi-arabia/.

"Medina Hotels." akses 28 April, 2016. https://www.expedia.co.id/ProphetsMosque-Hotels.0-16118152-0.Travel-Guide-Filter-Hotels?rfrr=Redirect.From.www.expedia.com\%2FProphets-Mosque-Hotels.0-16118152-0.TravelGuide-Filter-Hotels\&.

"OMEGA Watches: Al-Hussaini Trading Co, Medinah, Saudi Arabia.” Accessed May 6, 2016. http://www.omegawatches.com/stores/storedetails/1407/.

“RAYMOND WEIL Genève > Search > Swiss Luxury Watches.” akses 6Mai, 2016. http://www.raymond-weil.com/en/stores/search. 
http://search.ebscohost.com/login. aspx? direct=true\&scope $=$ site $\& \mathrm{db}=$ nlebk $\& \mathrm{db}=$ nlabk\&AN= 14037 .

"TAG Heuer Store Madina - Luxury Watches in Madina - Paris Gallery Rashid Madina.” Accessed May 6, 2016. http://store.tagheuer.com/143329-paris-gallery-rashid-madina.

"Weekly Promotion Madinah.” akses6 Mei, 2016. http://www.bindawood.com/ en/pro_madinah.html.

Winder, R. B. 1986. "Al-Madinah: Modern City." In The Encyclopaedia ofIslam, edited by C Edmund Bosworth, van Donzel, Bernard Lewis, and Ch. Pellat, V:998-1007. Leiden: Brill.

Nozol Royal Inn Hotel, Al Madinah, Saudi Arabia.” Booking.com. akses 30 April 2016. http://www.booking.com/hotel/sa/royal-inn.en-gb.html.

“Al Noor Mall.” Akses 26 Mei 2016. http://www.alnoormall.com/. 